\title{
BUBBLE FORMATION AT A SINGLE ORIFICE IN GAS-FLUIDISED BEDS
}

\author{
J. J. NIEUWLAND, M. L. VEENENDAAL, J. A. M. KUIPERS* and W. P. M. VAN SWAAIJ \\ Twente University of Technology, Department of Chemical Engineering, P.O. Box 217, 7500 AE Enschede, \\ The Netherlands
}

(First received 4 January 1995; accepted 12 January 1996)

\begin{abstract}
An earlier developed hydrodynamic model describing dense gas-solid two phase flow has been used to study the bubble formation process at a single orifice. A systematic experimental and theoretical study has been conducted to investigate the effect of particle properties (i.e. particle diameter and density) on the bubble growth process for Geldart type B powders. Theoretical results, obtained for both twodimensional and three-dimensional geometries, have been compared with experimental data and with predictions from approximate models reported in literature. A comparison of the theoretical results and experimental data shows that the advanced hydrodynamic model gives a satisfactory good description of the bubble growth process for several particle types which makes this model a useful tool to study the bubble formation process in fluidised beds. It appears that the influence of particle size and particle density on bubble formation can be related to the effect of the minimum fluidisation velocity on this process. At a constant gas injection rate through the orifice higher minimum fluidisation velocities result in larger bubbles and decreased leakage. Further, it has been found that coarse particles give rise to the formation of relatively elongated bubbles. The detachment times, on the other hand, seem to be independent of the particle size used. Copyright $\odot 1996$ Elsevier Science Ltd
\end{abstract}

Keywords: bubble formation, two-fluid model simulation, gas leakage.

\section{INTRODUCTION}

Many of the characteristic features of gas-fluidised beds, like their excellent heat and mass transfer properties, can be attributed to the presence of bubbles and are dominated by their behaviour. Therefore, the understanding of gas bubble behaviour is of crucial importance for fluidised bed reactor design.

The work of Kuipers et al. (1991), concerned with bubble formation at a single orifice in a two-dimensional gas-fluidised bed, has been extended to investigate the effect of solid particle properties on bubble formation. In addition, this process has been studied in a semi-circular gas-fluidised bed with one central orifice.

In gas-fluidised beds of practical interest the fluidising agent is normally injected through discrete holes or other orifices in the gas distributor plate which supports the bed. Bubble formation at discrete orifices has been studied experimentally and theoretically by a number of investigators. In the next section a short review will be presented of approximate bubble formation models which have been proposed in the literature.

\section{OVERVIEW OF EXISTING APPROXIMATE MODELS}

During the last few decades, several approximate models have been presented in the literature to describe bubble growth in gas-fluidised beds at a single

*Corresponding author. Tel.: +3153 4893039. Fax: +3153 4894738 orifice. The models proposed by Harrison and Leung (1961), Zenz (1968) and Caram and Hsu (1986) are based on the assumption of formation of spherical shaped bubbles which grow due to gas injection through the orifice while they exchange gas with the surrounding emulsion phase through the bubble boundary. In these models the injection flow rate $Q$ is considered to be constant during the formation process, while the exchange velocity $U_{\text {ex }}$ is assumed to be uniform over the bubble surface.

The differential equation describing the rate of change of the bubble volume $V$ with respect to time $t$ is given by:

$$
\frac{\mathrm{d} V}{\mathrm{~d} t}=Q-U_{\mathrm{ex}} A
$$

In eq. (1), $A$ denotes the bubble area and $U_{\text {ex }}$ the superficial exchange velocity through the bubble boundary.

The equation of motion for the bubble describes the position of the bubble centre $s$ as a function of time and is given by:

$$
\frac{\mathrm{d}}{\mathrm{d} t}\left(C_{0} \rho_{\mathrm{em}} V \frac{\mathrm{d} s}{\mathrm{~d} t}\right)=\rho_{\mathrm{e}} V\left|g_{z}\right|
$$

where $\rho_{\mathrm{em}}$ represents the emulsion phase density, $s$ the distance between the bubble centre and the orifice, $V$ the bubble volume and $C_{0}$ the virtual mass coefficient. The latter quantity accounts for the inertia of the emulsion phase which is associated with the growing bubble. The value of the virtual mass coefficient 
depends on the orifice geometry (Davidson and Harrison, 1963) and equals 1.0 (two-dimensional case) or $11 / 16$ (three-dimensional case) for the orifice type shown in Fig. 1.

In terms of the approximate models, bubble detachment occurs when $s=R$. Except for the case of $U_{\mathrm{ex}}=$ 0 , no analytical solutions of eqs (1) and (2) can be obtained and they must be integrated numerically to yield $R$ and $s$ as a function of time. The aforementioned models differ only with respect to the expressions used to represent the gas exchange between the bubble and the emulsion phase.

In the model proposed by Harrison and Leung (1961) it is assumed that there is no exchange of gas from the bubble to the surrounding emulsion phase:

$$
U_{\mathrm{ex}}=0
$$

However, there is considerable experimental evidence that significant gas leakage through the bubble boundary occurs (Nguyen and Leung, 1972; Rowe et al., 1979; Yang et al., 1984). Yang et al. (1984) developed a model to describe this phenomenon by assuming that, similar to the Zenz (1968) assumption, gas leaks out through the bubble boundary at a superficial velocity equivalent to the minimum fluidisation velocity:

$$
U_{\mathrm{ex}}=U_{m f}
$$

Another approach for modelling the gas exchange between the bubble and the emulsion phase has been followed by Caram and Hsu (1986). They applied Darcy's law to obtain an expression for the superficial

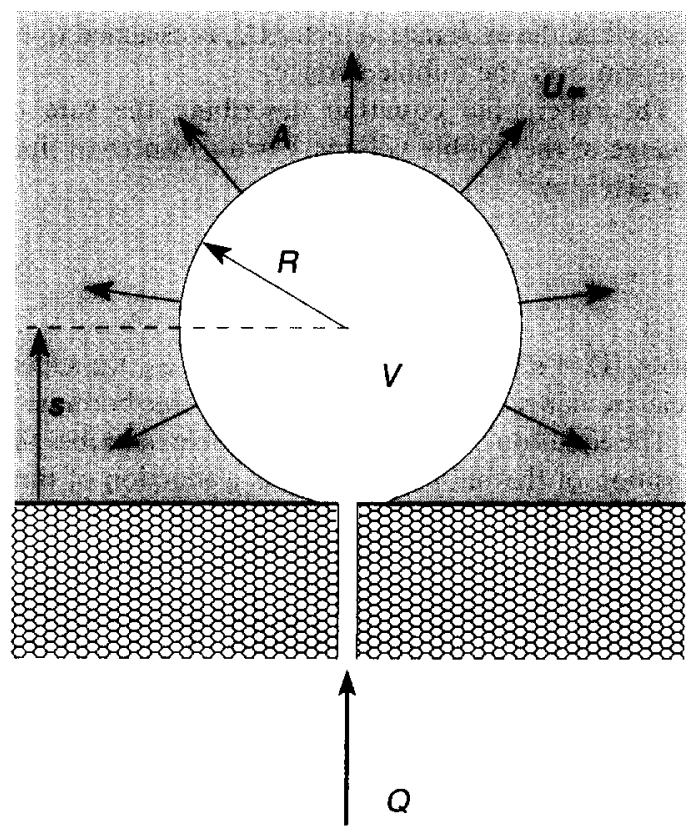

Fig. 1. Simplified representation of bubble formation at a single orifice in gas-fluidised beds. exchange velocity:

$$
U_{\mathrm{ex}}=-\left.K_{D} \frac{\partial P}{\partial r}\right|_{\mathbf{R}} .
$$

The permeability of the emulsion phase $K_{D}$ can in principle be obtained from the Blake-Kozeny equation (Bird et al., 1960) or alternatively from the known minimum fluidisation velocity:

$$
K_{D}=\frac{U_{m f}}{\rho_{\mathrm{em}}\left|g_{z}\right|} .
$$

To obtain an expression for the pressure gradient in eq. (5) a mechanical energy balance with respect to the emulsion phase is formulated. Assuming incompressible, inviscid and irrotational emulsion phase flow leads to the following conservation equation for mechanical energy:

$$
\frac{\partial}{\partial r}\left(\frac{\partial \phi}{\partial t}+k+\frac{P}{\rho_{\mathrm{em}}}\right)=0
$$

where in addition gravity has been neglected. In eq. (7) $\phi$ and $k$ denote, respectively, the velocity potential and kinetic energy of the emulsion phase where $k$ is given by:

$$
k=\frac{1}{2}\left(u_{\mathrm{em}} \cdot u_{\mathrm{em}}\right)
$$

Following this approach to obtain an expression for the exchange velocity yields:

$$
U_{\mathrm{ex}}=\frac{U_{m f}}{\left|g_{z}\right|}\left[\frac{1}{R}\left(\frac{\mathrm{d} R}{\mathrm{~d} t}\right)^{2}+\frac{\mathrm{d}^{2} R}{\mathrm{~d} t^{2}}\right]
$$

for a two-dimensional bubble and

$$
U_{\mathrm{ex}}=\frac{U_{m f}}{\left|g_{z}\right|}\left[\frac{3}{2 R}\left(\frac{\mathrm{d} R}{\mathrm{~d} t}\right)^{2}+\frac{\mathrm{d}^{2} R}{\mathrm{~d} t^{2}}\right]
$$

for a three-dimensional bubble.

The final model discussed here is the one developed by Pierrat and Caram (1992). They solved reduced two-fluid model equations, for solid phase mass and momentum conservation in one dimension, assuming spherical bubbles. Their mass and momentum conservation equations are given by:

$$
\begin{gathered}
\frac{\partial \varepsilon_{s} \rho_{s}}{\partial t}+\frac{1}{r^{2}} \frac{\partial}{\partial r}\left(\varepsilon_{s} r^{2} v \rho_{s}\right)=0 \\
\rho_{s} \varepsilon_{s}\left[\frac{\partial v}{\partial t}+v \frac{\partial v}{\partial r}\right]=\beta(u-v)-G \frac{\partial \varepsilon_{f}}{\partial r} .
\end{gathered}
$$

The last term in eq. (12) represents the normal particle-particle interaction force, and prevents the solid phase volume fraction to reach unacceptably low values. For the elasticity modulus $G$ the following generalised form holds:

$$
G=-G_{0} \mathrm{e}^{\mathfrak{c}\left(\varepsilon^{*}-\varepsilon\right)}
$$

in which $G_{0}$ represents a normalising units factor. Pierrat and Caram used $c=600$ and $\varepsilon_{f}^{*}=0.376$. 
The interphase momentum transfer coefficient $\beta$ is obtained from the well-known Ergun relation:

$\beta=150 \frac{\left(1-\varepsilon_{f}\right)^{2}}{\varepsilon_{f}} \frac{\mu_{f}}{d_{p}^{2}}+1.75\left(1-\varepsilon_{f}\right) \frac{\rho_{f}}{d_{p}}|u-v|$.

Bubble detachment times cannot be predicted with the Caram-Pierrat model because the equation of motion for the bubble is not included in their model.

\section{HYDRODYNAMIC MODEL}

\subsection{Governing equations}

The motion of a system of solid particles suspended in a Newtonian fluid can, at least in principle, be completely described by the Navier-Stokes equations for the fluid phase and the Newtonian equations of motion for each suspended particle. However, due to the huge number of particles, the number of equations is far too high to permit direct solution for systems of practical interest on present computer facilities. Therefore, the two-fluid approach has been adopted by different authors, treating both phases as a single continuous phase. Reviews concerning these kinds of models have been given by Gidaspow (1986) and Kuipers (1990). More recent developments, including a kinetic theory to model mutual particle interactions, are presented in Ding and Gidaspow (1990). Adopting the "two-fluid" concept for each phase, separate conservation equations for mass, momentum and thermal energy are used with appropriate interaction terms representing the coupling between the phases. Equations (13)-(16) show the mass and momentum conservation equations in vector form.

Continuity equation for the fluid phase:

$$
\frac{\partial\left(\varepsilon_{f} \rho_{f}\right)}{\partial t}+\left(\nabla \cdot \varepsilon_{f} \rho_{f} \mathbf{u}\right)=0
$$

Continuity equation for the solid phase:

$$
\frac{\partial\left(\varepsilon_{s} \rho_{s}\right)}{\partial t}+\left(\nabla \cdot \varepsilon_{s} \rho_{s} \mathbf{v}\right)=0
$$

Momentum equation for the fluid phase:

$$
\begin{aligned}
& \frac{\partial\left(\varepsilon_{f} \rho_{f} \mathbf{u}\right)}{\partial t}+\left(\nabla \cdot \varepsilon_{f} \rho_{f} \mathbf{u u}\right) \\
& \quad=-\varepsilon_{f} \nabla P-\beta(\mathbf{u}-\mathbf{v})-\left(\nabla \cdot \varepsilon_{f} \boldsymbol{\tau}_{f}\right)+\varepsilon_{f} \rho_{f} \mathbf{g} .
\end{aligned}
$$

Momentum equation for the solid phase:

$$
\begin{aligned}
& \frac{\partial\left(\varepsilon_{s} \rho_{s} \mathbf{v}\right)}{\partial t}+\left(\nabla \cdot \varepsilon_{s} \rho_{s} \mathbf{v v}\right) \\
& \quad=-\varepsilon_{s} \nabla P+\beta(\mathbf{u}-\mathbf{v})-\left(\nabla \cdot \varepsilon_{s} \tau_{s}\right)+\varepsilon_{s} \rho_{s} \mathbf{g}-\nabla P_{s} .
\end{aligned}
$$

The thermal energy equations have been omitted here due to the anticipated small heat effects during bubble formation in cold-flow fluidised beds. Due to the mathematical complexity of the transport equations a numerical solution procedure is required as de- scribed in more detail by Kuipers et al. (1993). The computer model developed by Kuipers et al. calculates the porosity, the pressure, the fluid phase temperature, the solid phase temperature and the velocity fields of both phases in two-dimensional Cartesian or axi-symmetrical cylindrical coordinates. These variables constitute the primary variables. To enable the solution of the transport equations (13)-(16) the remaining unknown variables have to be specified in terms of the primary variables by formulating the constitutive equations. These equations will be discussed briefly in the next section.

\subsection{Constitutive equations}

3.2.1. Fluid phase density $\rho_{\mathrm{f}}$ and solid phase density $\rho_{\mathrm{s}}$. The fluid phase density is related to pressure and fluid phase temperature by the ideal gas law:

$$
\rho_{f}=\frac{M_{f} P}{R_{g} T_{f}}
$$

where the fluid phase temperature $T_{f}$ is constant. For the solid phase, microscopic incompressibility has been assumed. As a consequence, a specified constant density $\rho_{\mathrm{s}, \mathrm{o}}$ was used:

$$
\rho_{s}=\rho_{s, 0}
$$

3.2.2. Interphase momentum transfer coefficient $\beta$. For porosities $\varepsilon_{f}<0.80$ the interphase momentum transfer coefficient $\beta$ has been obtained from the wellknown Ergun equation:

$\beta=150 \frac{\left(1-\varepsilon_{f}\right)^{2}}{\varepsilon_{f}} \frac{\mu_{f}}{d_{p}^{2}}+1.75\left(1-\varepsilon_{f}\right) \frac{\rho_{f}}{d_{p}}|\mathbf{u}-\mathbf{v}|$

whereas for porosities $\varepsilon_{f} \geqslant 0.80$ the following expression for the interphase momentum transfer coefficient has been derived from the correlation of Wen and $\mathrm{Yu}$ (1966):

$$
\beta=\frac{3}{4} C_{d, s} \frac{\varepsilon_{f}\left(1-\varepsilon_{f}\right)}{d_{p}} \rho_{f}|\mathbf{u}-\mathbf{v}| \varepsilon_{f}^{-2.65} .
$$

In eq. (20) the drag coefficient for a single particle $C_{d, s}$ depends on the particle Reynolds number $R e_{p}$ as given by Schiller and Naumann (1935):

$$
C_{d, s}= \begin{cases}\frac{24}{R e_{p}}+\frac{3.6}{R e_{p}^{0.313}}, & R e_{p}<1000 \\ 0.44, & R e_{p} \geqslant 1000 .\end{cases}
$$

3.2.3. Fluid phase viscous stress tensor $\tau_{\mathrm{f}}$ and solid phase viscous stress tensor $\tau_{\mathrm{s}}$. The viscous stress tensors $\tau_{f}$ and $\tau_{s}$ are expected to depend in a complex manner on the void fraction and the spatial derivatives of the locally averaged velocities $u$ and $\mathbf{v}$. At present, a unified rheological model of fluidised suspensions is not yet available and therefore it has been assumed that $\tau_{f}$ is related only to the fluid motion, 
and $\tau_{s}$ only to the solid motion and that both have the general Newtonian fluid form (Bird et al., 1960):

$$
\begin{gathered}
\boldsymbol{\tau}_{f}=-\left[\left(\xi_{f}-\frac{2}{3} \mu_{f}\right)(\nabla \cdot \mathbf{u}) \mathbf{I}+\mu_{f}\left((\nabla \mathbf{u})+(\nabla \mathbf{u})^{T}\right)\right] \\
\boldsymbol{\tau}_{s}=-\left[\left(\xi_{s}-\frac{2}{3} \mu_{s}\right)(\nabla \cdot \mathbf{v}) \mathbf{I}+\mu_{s}\left((\nabla \mathbf{v})+(\nabla \mathbf{v})^{T}\right)\right]
\end{gathered}
$$

where $\xi_{f}$ and $\xi_{s}$ denote the bulk viscosities of the fluid phase and solid phase, respectively, and $\mu_{f}$ and $\mu_{s}$ denote the shear viscosities of both phases. In the actual computations reported in this paper, the bulk viscosities of both phases have been set equal to zero (Bird et al., 1960) whereas for the shear viscosities the following constant values have been taken:

$$
\begin{gathered}
\mu_{f}=2 \times 10^{-5} \mathrm{~kg} \mathrm{~m}^{-1} \mathrm{~s}^{-1} \\
\mu_{s}=1.0 \mathrm{~kg} \mathrm{~m}^{-1} \mathrm{~s}^{-1}
\end{gathered}
$$

The value of the solid phase shear viscosity is based on measurements reported by Schgerl et al. (1961) and Hagyard and Sacerdote (1966). These authors show a slight dependence of the solid phase shear viscosity on particle diameter, but in this work a mean value is used for all particle types. A sensitivity study to the value of the solid phase shear viscosity, moreover, revealed that the viscous transport mechanism plays only a minor role.

3.2.4. Solid phase pressure $P_{\mathrm{s}}$. The constitutive equation for the solid phase pressure $P_{s}$ is expressed as a function of the void fraction $\varepsilon_{f}$ by:

$$
\nabla P_{s}=G\left(\varepsilon_{f}\right) \nabla \varepsilon_{f}
$$

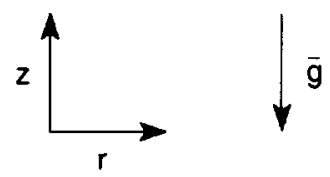

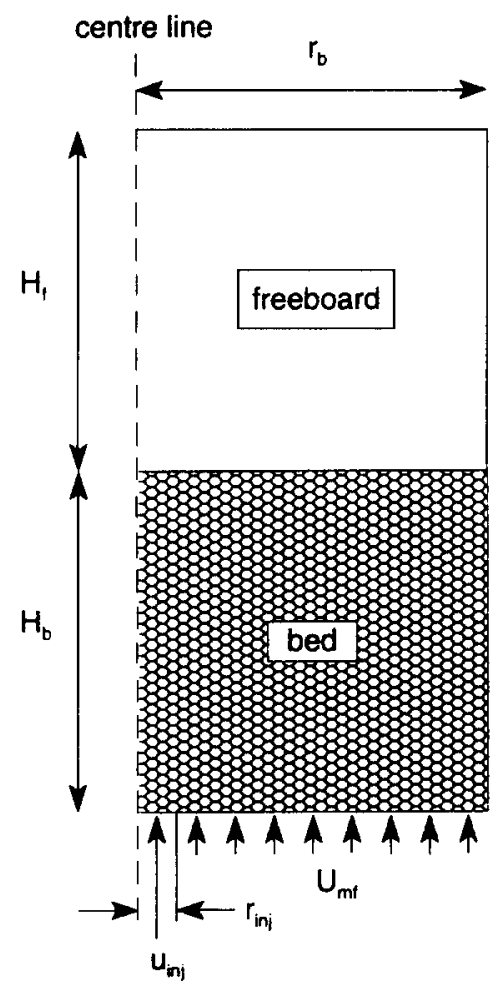

Geometry centre line

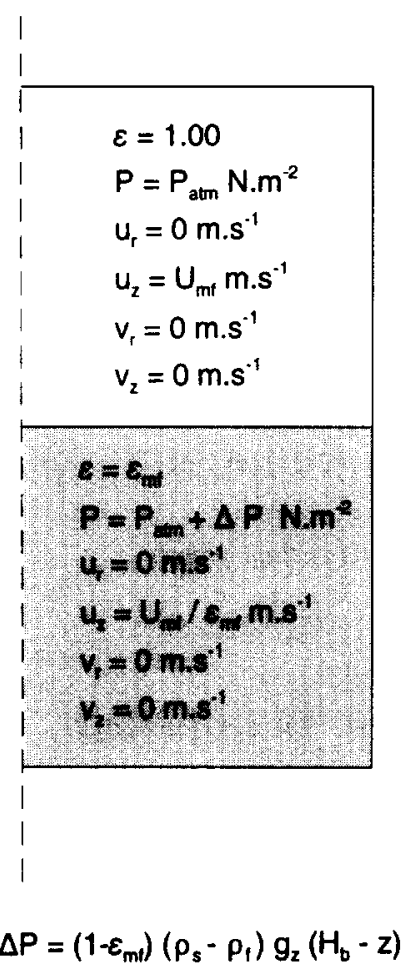

Initial conditions

Fig. 2. Initial and boundary conditions for the numerical solution of bubble formation in gas-fluidised beds. 
where $G\left(\varepsilon_{f}\right)$ represents the solid phase elasticity modulus defined by:

$$
G\left(\varepsilon_{f}\right)=\frac{\mathrm{d} P_{s}}{\mathrm{~d} \varepsilon_{f}} .
$$

This modulus has been incorporated in the model according to the following generalised form:

$$
G\left(\varepsilon_{f}\right)=-G_{0} \mathrm{e}^{\left(\mathcal{c}\left(\varepsilon_{f}^{*}-\varepsilon_{f}\right)\right.}
$$

where $G_{0}$ represents the normalising units factor, $c$ the compaction modulus and $\varepsilon_{f}^{*}$ the compaction gas phase volume fraction. To prevent unacceptable bed compaction, $G_{0}$ has been taken as $1.0 \mathrm{~Pa}$, with $c=100$ and $\varepsilon_{f}^{*}=0.45$. These values result in a more gradual increase of the elasticity modulus for decreasing porosities below $\varepsilon_{f, m f}$ than the values used by Pierrat and Caram [eq. (13)]. Gidaspow and Ettehadieh (1983) performed a sensitivity study for different values for $c$ and $\varepsilon_{f}^{*}$, but found minimal influence on the bubble formation process.

\subsection{Numerical simulation}

To obtain a unique solution to the system of partial differential equations, supplemented with the constitutive equations, unique initial and boundary conditions in terms of the basic variables are required. Figure 2 shows the initial and boundary conditions used for the numerical simulation of bubble formation in cold-flow gas-fluidised beds with one central orifice, while the corresponding numerical data are listed in Table 1.

The right wall of the bed has been modelled as a no-slip rigid wall for both phases. At the centre of the bed a fictitious free-slip rigid wall was defined to represent symmetry around the centre line of the fluidised bed. At the bottom wall the mass flux of the fluid phase was prescribed whereas for the solid phase this wall represents a no-slip rigid wall. At the top of the bed a continuous outflow wall and a no-slip rigid wall were assumed for the fluid phase and solid phase, respectively. As shown in Fig. 2 a freeboard of the same height as the initial bed height was provided to allow for bed expansion.

In all computations reported in this paper the minimum fluidisation condition was used as the initial condition. At zero time the gas injection velocity through the orifice was increased instantaneously from minimum fluidisation velocity to the required injection velocity $u_{\text {inj }}$, where:

$$
u_{\mathrm{inj}}=\frac{Q}{A_{o}} .
$$

\subsection{Post processing of the numerical solution}

Our computer model calculates the porosity, the pressure and the velocities of both phases at discrete positions in the computational domain as a function of time. To extract bubble diameters from the numer-

\begin{tabular}{|c|c|c|}
\hline & Two-dimensional & Three-dimensional \\
\hline Geometry & $\begin{array}{c}r_{0}=0.0075 \mathrm{~m} \\
W=0.285 \mathrm{~m} \\
H_{b}=0.500 \mathrm{~m} \\
H_{f}=0.500 \mathrm{~m}\end{array}$ & $\begin{array}{l}r_{0}=0.0050 \mathrm{~m} \\
W=0.150 \mathrm{~m} \\
H_{b}=0.500 \mathrm{~m} \\
H_{f}=0.750 \mathrm{~m}\end{array}$ \\
\hline \multirow[t]{2}{*}{ Grid size } & $\begin{array}{c}n x=38 \\
\delta x=0.0075 \mathrm{~m}\end{array}$ & $\begin{array}{c}n x=60 \\
\delta x=0.0025 \mathrm{~m}\end{array}$ \\
\hline & $\begin{array}{c}n y=80 \\
\delta y=0.0125 \mathrm{~m}\end{array}$ & $\begin{array}{c}n y=125 \\
\delta y=0.0100 \mathrm{~m}\end{array}$ \\
\hline $\begin{array}{l}\text { Used } \\
\text { time-step }\end{array}$ & $\delta t=1.25 \times 10^{-4} \mathrm{~s}$ & $\delta t=1.00 \times 10^{-4} \mathrm{~s}$ \\
\hline $\begin{array}{l}\text { Injection } \\
\text { rates }\end{array}$ & $u_{\mathrm{inj}}=10 \mathrm{~m} \mathrm{~s}^{-1}$ & $u_{\mathrm{inj}}=10,20,30 \mathrm{~m} \mathrm{~s}^{-1}$ \\
\hline $\begin{array}{l}\text { Bed } \\
\text { voidage }\end{array}$ & $\varepsilon_{m f}=0.402$ & $\varepsilon_{m f}=0.402$ \\
\hline Particles & $\begin{array}{c}140 \mu \mathrm{m}<d_{p}<750 \mu \mathrm{m} \\
0.02<U_{m f}<0.44 \mathrm{~m} \mathrm{~s}^{-1}\end{array}$ & $\begin{array}{l}275 \mu \mathrm{m}<d_{p}<655 \mu \mathrm{m} \\
0.08<U_{m f}<0.40 \mathrm{~m} \mathrm{~s}^{-1}\end{array}$ \\
\hline
\end{tabular}
ically calculated porosity distributions it is necessary
Table 1. Data for numerical simulations (see also Fig. 2)

to define a bubble contour. For the two-dimensional geometry an equivalent bubble diameter is defined as the diameter of a circle possessing the same area as the numerically computed area $S$ for which $\varepsilon_{f}>0.85$. For the three-dimensional geometry the equivalent bubble diameter was defined as the diameter of a sphere with the same volume as the numerical computed volume $V$ for which $\varepsilon_{f}>0.85$. These definitions lead to the following expressions for the equivalent bubble diameters in the two-dimensional and three-dimensional cases:

In two dimensions:

$$
D_{e}=\sqrt{\frac{S}{(1 / 4) \pi}}
$$

In three dimensions:

$$
D_{e}=\sqrt[3]{\frac{V}{(1 / 6) \pi}} .
$$

\section{EXPERIMENTAL}

\subsection{Equipment and experimental procedure}

The experiments were carried out in a thin twodimensional gas-fluidised bed and in a semicircular three-dimensional gas-fluidised bed as shown schematically in Fig. 3. A two-dimensional bed offers the possibility of visual observation of the bed behaviour, for instance, by photography. However, the front and rear walls influence the fluidisation behaviour to some extent which might complicate the experimental validation of two-dimensional hydrodynamic models since these models do not take the front and rear walls into account. In comparison with the two-dimensional bed the semicircular bed offers the possibility to observe gas bubble behaviour in a geometry which is closer to the geometry of real life fluidised beds. In the semicircular bed there is only one smooth glass plate influencing the bed hydrodynamics, whereas there are two plates in the two-dimensional bed. 
sintered porous plate

(average pore size $14 \mu \mathrm{m}$ ) sintered porous plate

(average pore size $10 \mu \mathrm{m}$ ) semi circular orifice

(covered with wire)
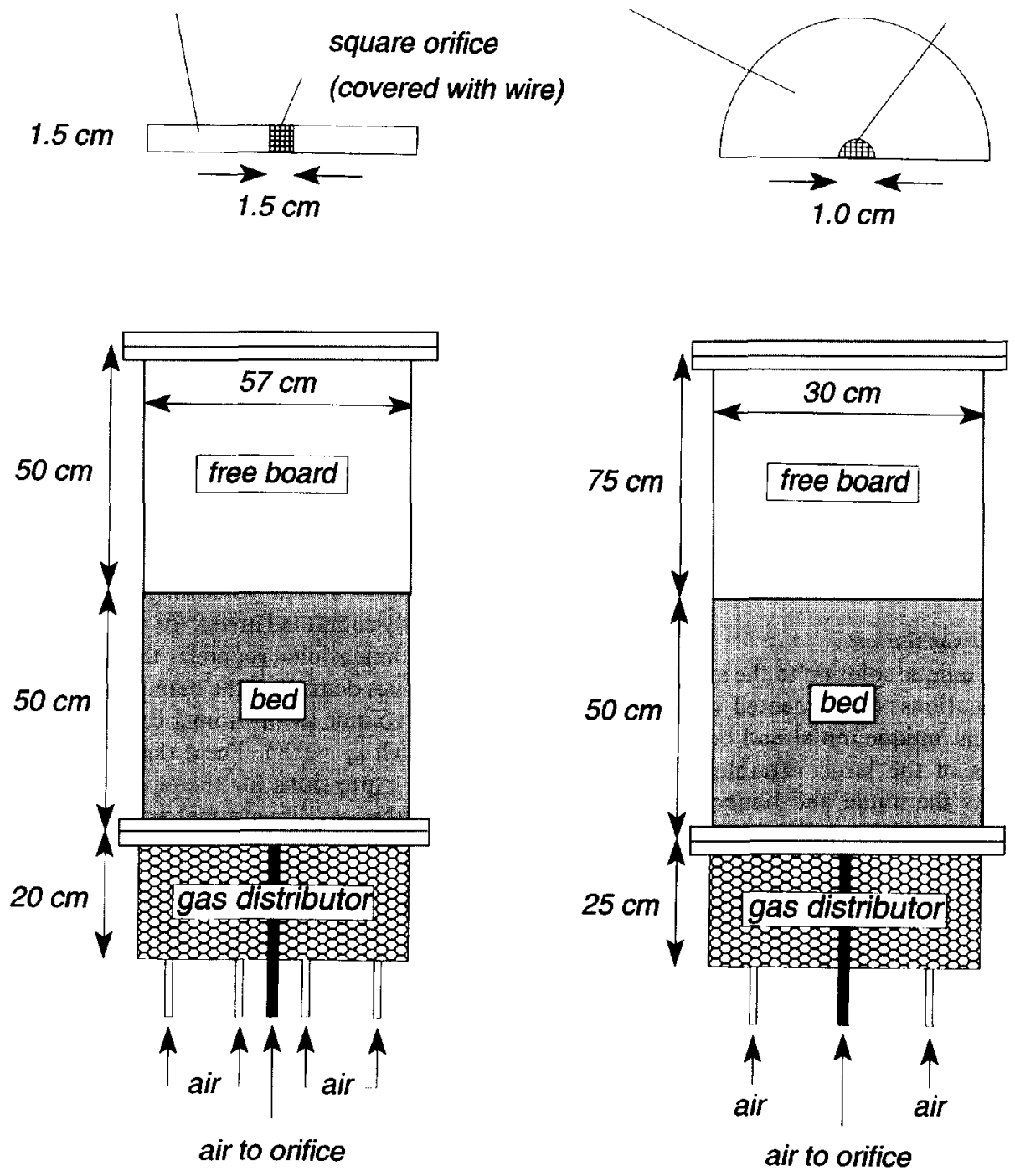

Fig. 3. Schematic representation of the experimentally used two-dimensional and three-dimensional gasfluidised beds.

The two-dimensional bed consists of a fluidised bed section built of $0.015 \mathrm{~m}$ thick glass plates (internal bed dimensions: $0.57 \mathrm{~m}$ width, $1.00 \mathrm{~m}$ height and $0.015 \mathrm{~m}$ depth) and a gas distributor section made of $0.015 \mathrm{~m}$ thick Plexiglas plates. The gas distributor section has a height and depth of $0.25 \mathrm{~m}$ and $0.015 \mathrm{~m}$, respectively. The primary fluidising gas (i.e. air) is supplied through 4 inlets which are equally distributed over the bottom section of the gas distributor. This section is filled with $3 \mathrm{~mm}$ glass beads to promote a homogeneous gas flow distribution over the distributor cross section. Primary fluidisation gas is introduced in the fluidised bed section through a porous sintered stainless steel plate with a mean pore diameter of $14 \mu \mathrm{m}$. The porous plate which serves as the main distributor of the primary fluidising gas was provided with a central rectangular pipe, covered with a stainless steel wire mesh, to inject secondary fluidising gas. During the experiments three different gas flow rates were adjusted independently by means of calibrated thermal mass flow controllers: a gas flow through the distributor section to keep the bed under conditions of minimum fluidisation, a gas flow through the rectangular orifice to fluidise the particles above the orifice and a gas flow to form the bubble at the orifice. Prior to bubble injection, the secondary gas was purged, while the support gas flowed through the gas distributor and orifice to keep the bed under conditions of minimum fluidisation. Rapidly responding magnetic valves, controlled by a micro computer (DOS-XT), were used to inject gas into the fluidised bed and purge the support gas during the injection.

The semicircular gas-fluidised bed was constructed from a glass tube with a wall thickness of $0.005 \mathrm{~m}$ and 
an internal diameter of $0.30 \mathrm{~m}$. This tube was cut in the axial direction into two equal parts. A $0.005 \mathrm{~m}$ thick glass plate was mounted at the open side to form a semicircular fluidised bed section $1.25 \mathrm{~m}$ in height. A stainless steel semicircular gas distributor section, filled with $4 \mathrm{~mm}$ glass beads, was connected to the semicircular fluidised bed section. Gas was supplied to the distributor at 3 positions, equally distributed over the bottom section, and entered the fluidised bed through a sintered stainless steel bottom plate (mean pore diameter: $10 \mu \mathrm{m})$. A semicircular orifice $(0.01 \mathrm{~m})$ was used to inject gas into the fluidised bed. Gas flows were controlled with a technique similar to the one applied for the two-dimensional bed. The bed material consisted of spherical solid particles with a narrow size range. All important particle properties are listed in Table 2 for both the two-dimensional bed and the semicircular bed. For convenience, the experimentally determined minimum fluidisation has been included in this table. This quantity was obtained in the usual way by determining the point of intersection of the bed pressure drop vs fluidising velocity curves for fixed bed and fluidised flow regimes.

\subsection{Measurement of bubble properties}

In this study flash photography in a darkened room was applied to register the process of bubble formation. The shutter of a camera (Nikon, F301), which was positioned in front of the equipment, was opened just before the gas injection was started. At the rear side of the fluidised bed a flashlight was generated with an accurately known time delay with respect to the moment of initiation of gas injection. After the light flash the shutter of the camera was closed. By applying increasing time delays between the gas injection and the triggering of the flashlight, the whole process of bubble formation could be registered. A transparent measuring grid on the front side made it possible to determine the size of the developing bubble surface from the photographs. Equivalent bubble diameters were defined as the diameter of a circle with equal surface as the experimentally determined bubble area [eq. (32)].

For the semicircular gas-fluidised bed a slightly modified photographic technique was used. In this

Table 2. Particle properties of the bed material used in the experiments

\begin{tabular}{|c|c|c|c|}
\hline $\begin{array}{l}d_{p} \\
(\mu \mathrm{m})\end{array}$ & $\begin{array}{c}\rho_{s} \\
\left(\mathrm{~kg} \mathrm{~m}^{-3}\right)\end{array}$ & $\underset{\left(\mathrm{m} \mathrm{s}^{-1}\right)}{U_{m f}}$ & Material \\
\hline \multicolumn{4}{|c|}{ Two-dimensional bed } \\
\hline 140 & 2920 & 0.019 & glass \\
\hline 285 & 3060 & 0.080 & glass \\
\hline 500 & 2930 & 0.219 & glass \\
\hline 750 & 2900 & 0.413 & glass \\
\hline 460 & 1435 & 0.096 & PVC \\
\hline \multicolumn{4}{|c|}{ Semicircular bed } \\
\hline 275 & 3060 & 0.075 & glass \\
\hline 550 & 2940 & 0.258 & glass \\
\hline 655 & 2900 & 0.338 & glass \\
\hline
\end{tabular}

case the bed was illuminated at the front side. Short shutter times $(<1 / 2000 \mathrm{~s})$ could be applied by using ISO-400 films in combination with illumination of the flat face of the bed by a powerful $500 \mathrm{~W}$ halogen lamp. Bubble volumes could be determined from the photographs, by assuming that the observed width at a certain height equals the diameter of a circular slice of the bubble with vertical dimension $\Delta y_{i}$ :

$$
V=\sum_{i=1}^{N} \frac{1}{4} \pi d_{i}^{2} \Delta y_{i} .
$$

An equivalent bubble diameter was defined as the diameter of a sphere with equal volume as the experimentally derived bubble volume, obtained from eq. (33).

All experimental data presented in this study are based on two or more measurements for a fixed set of operating conditions.

\section{RESULTS}

Bubble formation at a single orifice has been studied experimentally, varying injection velocities through the orifice, particle sizes and particle densities. Physical properties of the particles which have been used in this study are listed in Table 2. Injection velocities through the orifice were varied from 5 to $15 \mathrm{~m} \mathrm{~s}^{-1}$ for the two-dimensional bed and from 10 to $30 \mathrm{~m} \mathrm{~s}^{-1}$ for the semicircular bed. Theoretically calculated and experimentally observed bubble formation in both the two-dimensional and semicircular gas-fluidised bed will be discussed for several particle types and gas injection rates through the orifice. In addition, the theoretical and experimental results will be compared with data obtained from the approximate bubble formation models discussed in Section 2.

\subsection{The bubble formation process}

As stated in Section 3.4, the bubble contour is taken at $\varepsilon_{f}=0.85$. Figure 4 shows a number of porosity contours $(0.80,0.85$ and 0.90 , respectively) for a bubble, which has just detached from the orifice $\left(d_{p}=500 \mu \mathrm{m}, \rho_{s}=2930 \mathrm{~kg} \mathrm{~m}^{-3}\right.$ and $\left.u_{\mathrm{inj}}=10.0 \mathrm{~m} \mathrm{~s}^{-1}\right)$. From this figure it can be seen that very strong porosity gradients exist near the bubble base whereas these gradients are considerably weaker near the bubble roof. Despite the fact that some sensitivity with respect to the selected porosity contour exists, in the present study $\varepsilon_{f}=0.85$ has been chosen to define the bubble contour.

In Fig. 5 the $\varepsilon_{f}=0.85$ contour is given for calculations with a coarse $(38 \times 80=3040$ cells $)$ and a fine $(76 \times 160=12160$ cells $)$ grid. It can be seen that the differences are sufficiently small to justify the use of the coarse grid.

Figure 6 shows a comparison of photographs with corresponding density plots for bubble formation in a two-dimensional gas-fluidised bed of $285 \mu \mathrm{m}$ glass beads. In this case a gas injection velocity of $10 \mathrm{~m} \mathrm{~s}^{-1}$ was applied through the orifice. The density plots 
have been obtained according to a procedure described in more detail elsewhere (Kuipers et al., 1992). From Fig. 6 a reasonable similarity between the photographs and the density plots can be observed. However, the agreement between theory and experiment is not perfect which can be attributed to the relatively coarse computational grid $(\delta x=0.75 \mathrm{~cm}$, $\delta y=1.00 \mathrm{~cm}$ ) applied in the computations.

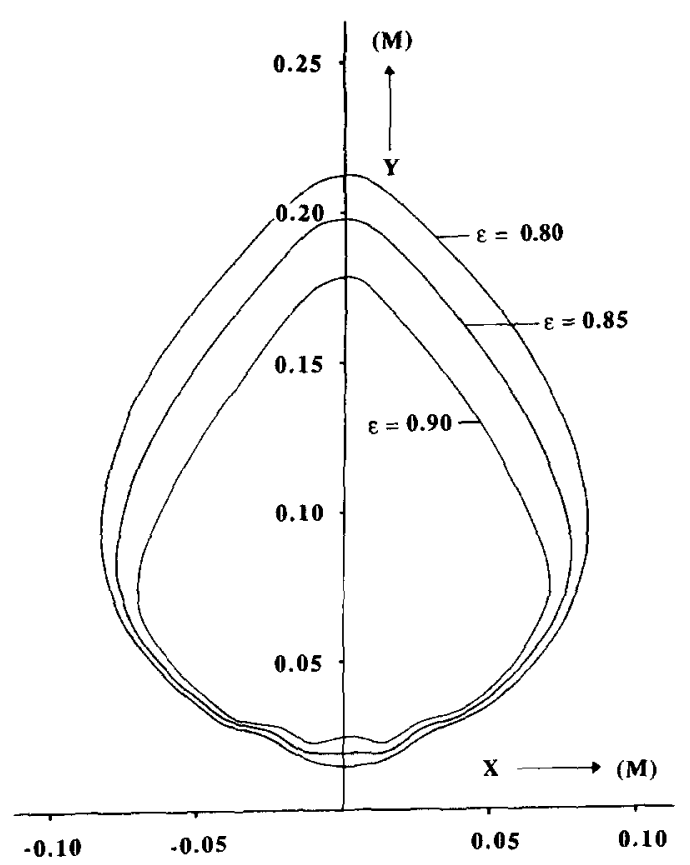

Fig. 4. Different bubble contours for a bubble in a twodimensional fluidised bed which has detached from the orifice; $d_{p}=500 \mu \mathrm{m}, \rho_{s}=2930 \mathrm{~kg} \mathrm{~m}^{-3}, u_{\mathrm{inj}}=10 \mathrm{~m} \mathrm{~s}^{-1}$.

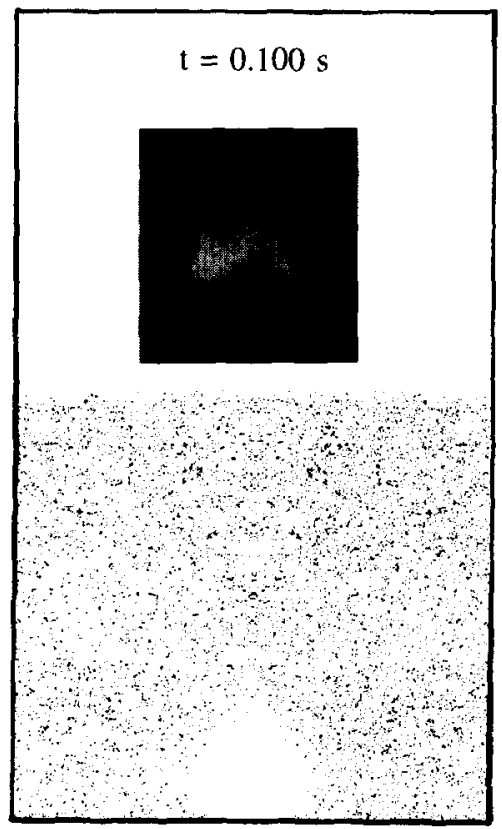

Figure 7 allows a quantitative comparison of the theoretically calculated and experimentally determined bubble sizes as a function of time. The results obtained from the approximate models, discussed in Section 2, are also included in this figure. To obtain the bubble diameter from the numerically calculated porosity distribution, the bubble contour was defined as a void fraction of 0.85 . This particular choice

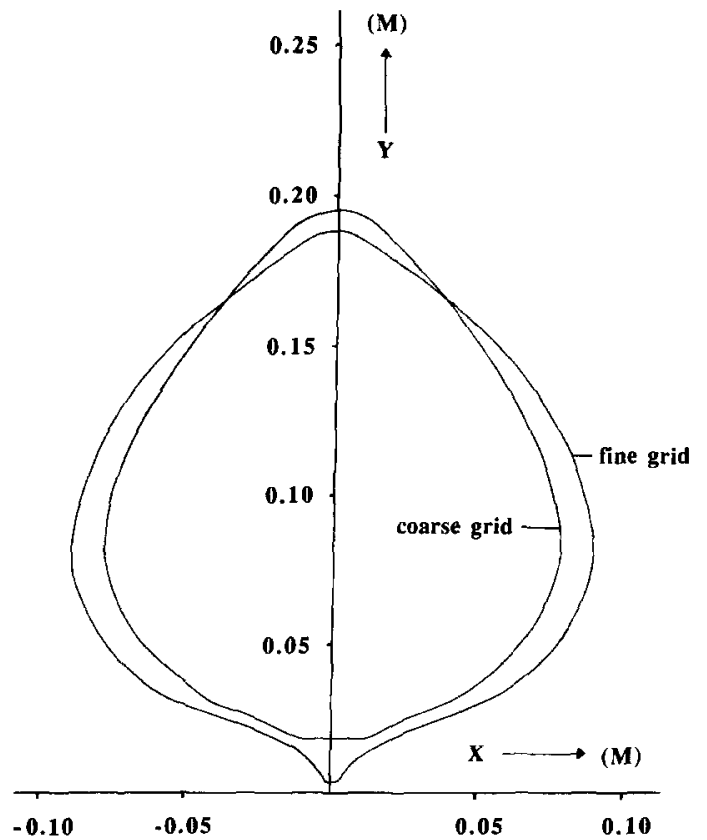

Fig. 5. The $\varepsilon=0.85$ contours for a detached bubble in a two-dimensional fluidised bed calculated using a coarse grid (3040 cells) and a fine grid $(12,160$ cells $) ; d_{p}=500 \mu \mathrm{m}, \rho_{s}=$ $2930 \mathrm{~kg} \mathrm{~m}^{-3}, u_{\mathrm{inj}}=10 \mathrm{~ms}^{-1}$.

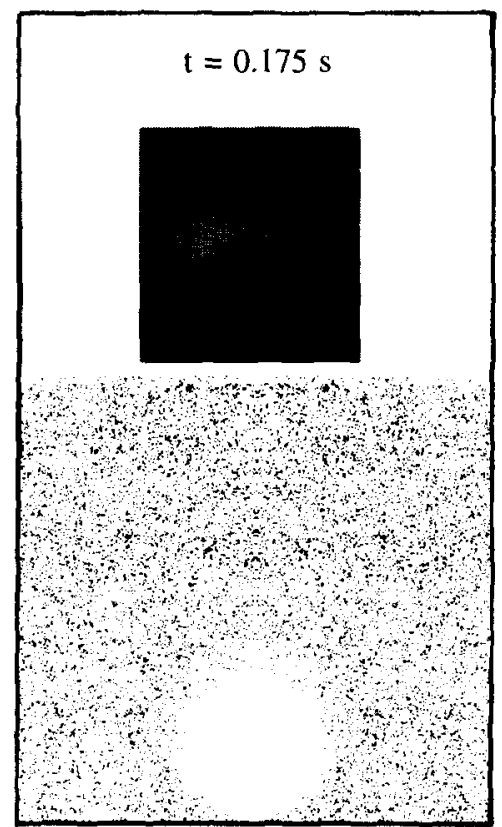

Fig. 6. Photographically observed and theoretically calculated bubble in a two-dimensional gas-fluidised bed; $d_{p}=285 \mu \mathrm{m}, \rho_{\mathrm{s}}=3060 \mathrm{~kg} \mathrm{~m}^{-3}, u_{\mathrm{inj}}=10 \mathrm{~m} \mathrm{~s}^{-1}$. 
defines the bubble boundary as a contour with very strong porosity gradients, especially near the bubble base. The end of the curves shown in Fig. 7 correspond to the moment of bubble detachment, except for the Caram-Pierrat model which does not predict a detachment time. From Fig. 7 it can be seen that the theoretically calculated bubble size from the two-fluid model agrees well with the experimental data. A similar degree of agreement has been obtained for the other particles used. Comparison of the experimental data with the results predicted by the Harrison and Leung model leads to the conclusion that considerable gas leakage through the bubble surface occurs. Through the introduction of the integral leakage fraction $\psi(t)$ defined by

$$
\psi(t)=\frac{Q t-V(t)}{Q t}
$$

this phenomenon can be quantified. In expression (35) $Q$ denotes the injection flow rate (orifice area times orifice velocity). The integral leakage fraction denotes the fraction of the injected gas which has leaked from the bubble to the emulsion phase during its formation. In Fig. 8 this quantity is shown as a function of time for the discussed models and for the experimental data. The experimental data clearly show that the strongest leakage occurs during the initial stage of bubble formation, and that the leakage decreases with time. The Harrison and Leung model, of course, does not account for this phenomenon. The Zenz model, which assumes a constant exchange velocity during the formation process, produces in deviation from experimental results an increasing leakage fraction as a function of time. This increase is due to the increasing exchange area during evolution of the bubble formation process. The models proposed by Caram and Hsu and Pierrat and Caram qualitatively agree with the experimental data, but in general the Two Fluid Model (TFM) provides a better quantitative description.

All approximate bubble formation models assume a uniform exchange velocity over the bubble surface. This assumption is incorrect as discussed by Hailu et al. (1993) and as evident from Fig. 9 which shows the superficial exchange velocity at the bubble boundary. From this figure it can be seen that emulsion phase gas flows into the bubble at its base, whereas bubble gas flows into the emulsion phase at the bubble roof. Figure 10 shows a comparison between the theoretically obtained results and the experimental data for bubble formation in the three-dimensional situation. The experimentally determined bubble diameters fall considerably below the theoretically calculated bubble diameters. This might be due to the presence of the front wall which restricts the movement of the emulsion phase and thereby induces penetration of the cavity in a direction away from the flat front wall. A similar degree of agreement has been obtained for the other particles used.

Of all the theoretical models considered here the TFM predicts the smallest bubbles and therefore gives the best agreement with the experimental data.

\subsection{Influence of particle properties}

5.2.1. Influence on bubble dimensions. The influence of the particle properties has been studied both

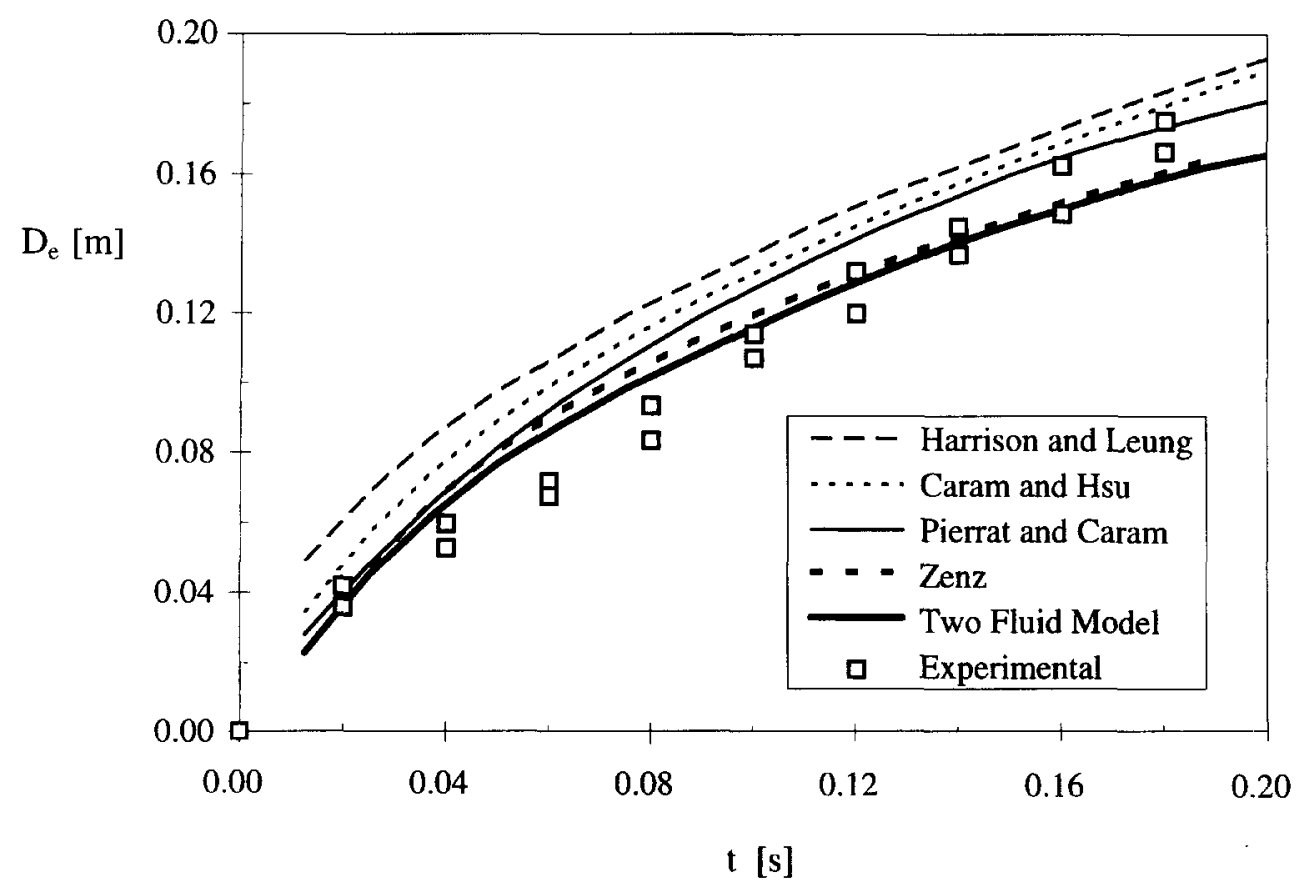

Fig. 7. Experimentally observed and theoretically calculated bubble growth in a two-dimensional gasfluidised bed; $d_{p}=285 \mu \mathrm{m}, \rho_{s}=3060 \mathrm{~kg} \mathrm{~m}^{-3}, u_{\mathrm{inj}}=10 \mathrm{~m} \mathrm{~s}^{-1}$. 


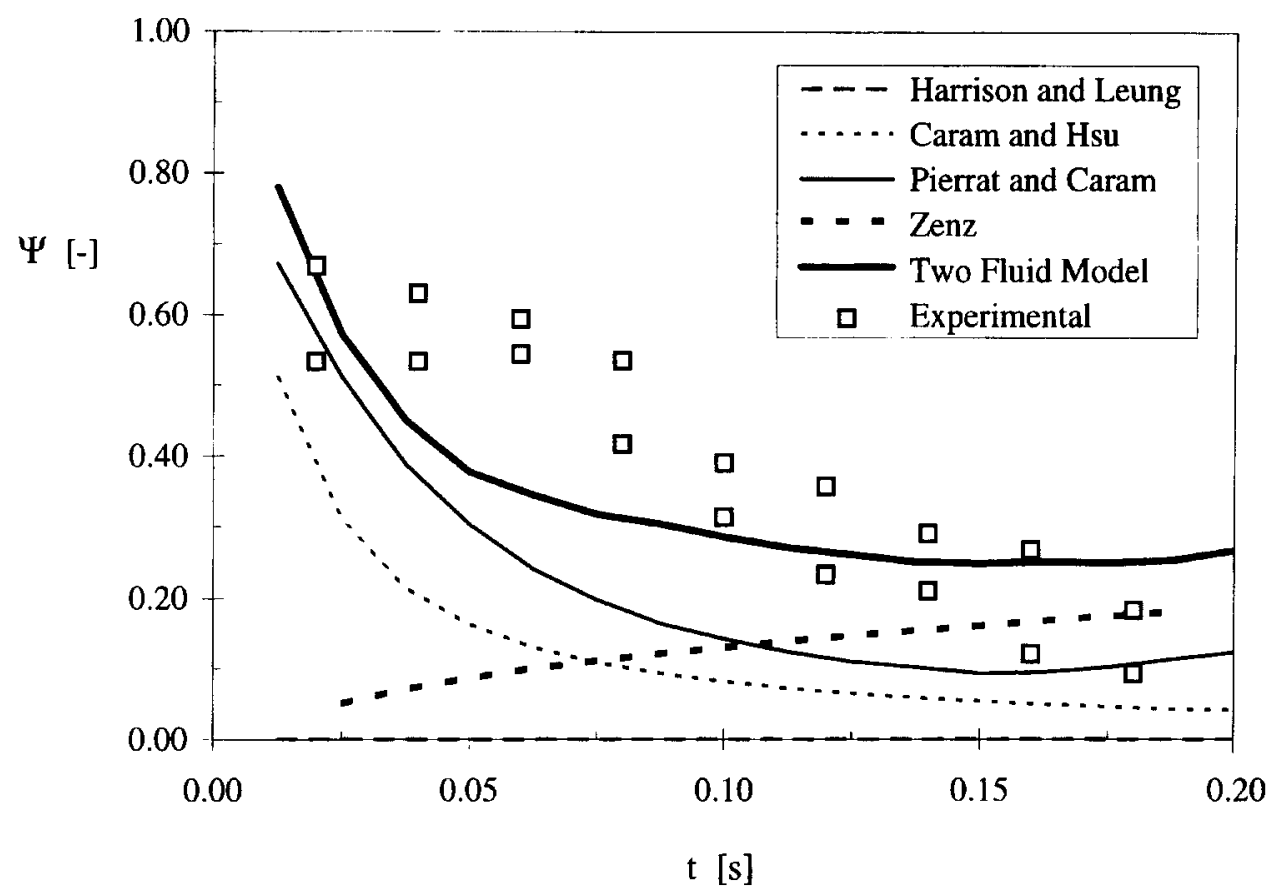

Fig. 8. Integral leakage fraction, defined by eq. (35), as a function of time for bubble growth in a twodimensional gas-fluidised bed; $d_{p}=285 \mu \mathrm{m}, \rho_{s}=3060 \mathrm{~kg} \mathrm{~m}^{-3}, u_{\mathrm{inj}}=10 \mathrm{~m} \mathrm{~s}^{-1}$.

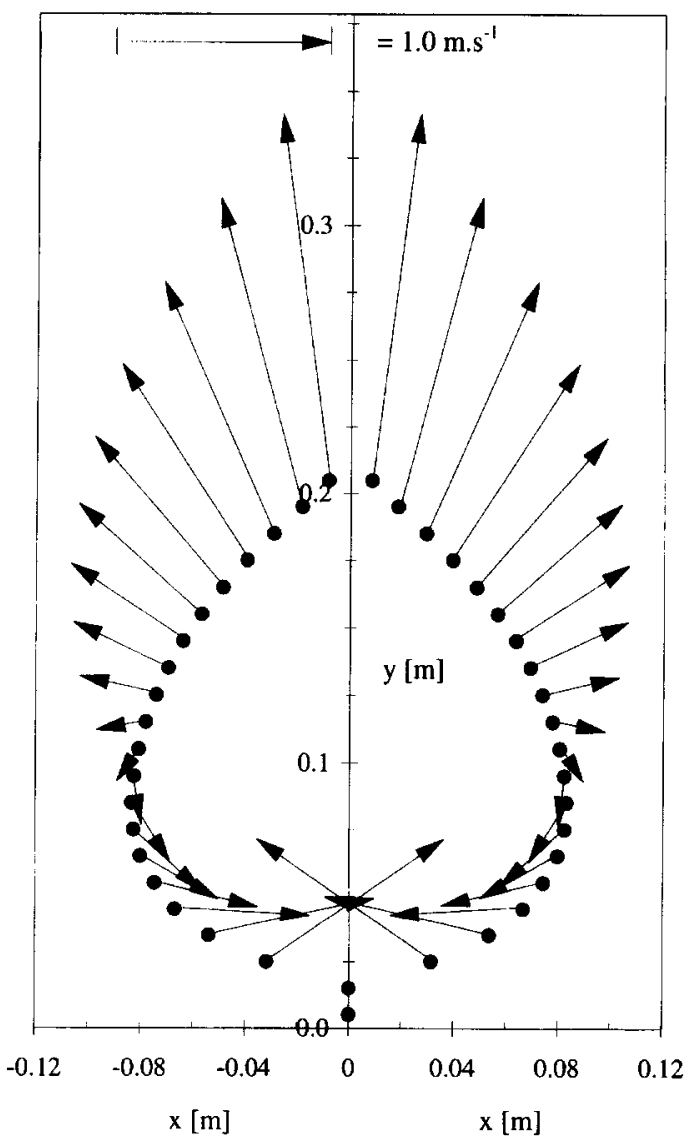

Fig. 9. Theoretically calculated interstitial exchange velocity over the bubble boundary in a two-dimensional gas-fluidised bed for a bubble which just detaches. Not shown is the velocity at the bottom $\left(10.3 \mathrm{~m} \mathrm{~s}^{-1}\right) ; d_{p}=285 \mu \mathrm{m}, \rho_{s}=$ $3060 \mathrm{~kg} \mathrm{~m}^{-3}, u_{\mathrm{inj}}=10 \mathrm{~m} \mathrm{~s}^{-1}, t=0.2 \mathrm{~s}$. theoretically and experimentally. All models, except the model suggested by Harrison and Leung, predict smaller bubbles with increasing particle diameters which is in agreement with the experimental observations. Figure 11 shows the theoretically calculated leakage fraction during bubble growth in a two-dimensional gas-fluidised bed. Computations were carried out for glass particles $\left(d_{p}=140,285,500\right.$ and $750 \mu \mathrm{m})$ and PVC-particles $\left(d_{p}=460 \mu \mathrm{m}\right)$. A comparison of the curves for the $460 \mu \mathrm{m}$ PVC powder and the $500 \mu \mathrm{m}$ glass beads shows the effect of particle density: the leakage increases with increasing particle density, resulting in smaller bubbles.

The dominant forces, related to the particulate phase, during the bubble formation process are gravity and the interphase momentum transfer. Because these forces determine the minimum fluidisation velocity $U_{m f}$ as well, the effect of this parameter has been studied in more detail. Several calculations were performed, using the TFM, for series with different particle properties, whereas the minimum fluidisation velocity remained constant within a series.

Table 3 lists the particle properties for two of these series. These data have been used to construct Fig. 12, displaying the integral leakage as a function of time. The close agreement between the curves of a certain series demonstrates the determinative role of the minimum fluidisation velocity. This conclusion is confirmed by the results of other series as well.

5.2.2. Influence on bubble shapes. The TFM also predicts the bubble shape, in contrast with the other models which only consider spherical or circular bubbles. Therefore, the effect of particle diameter on bubble shape has been studied theoretically and 


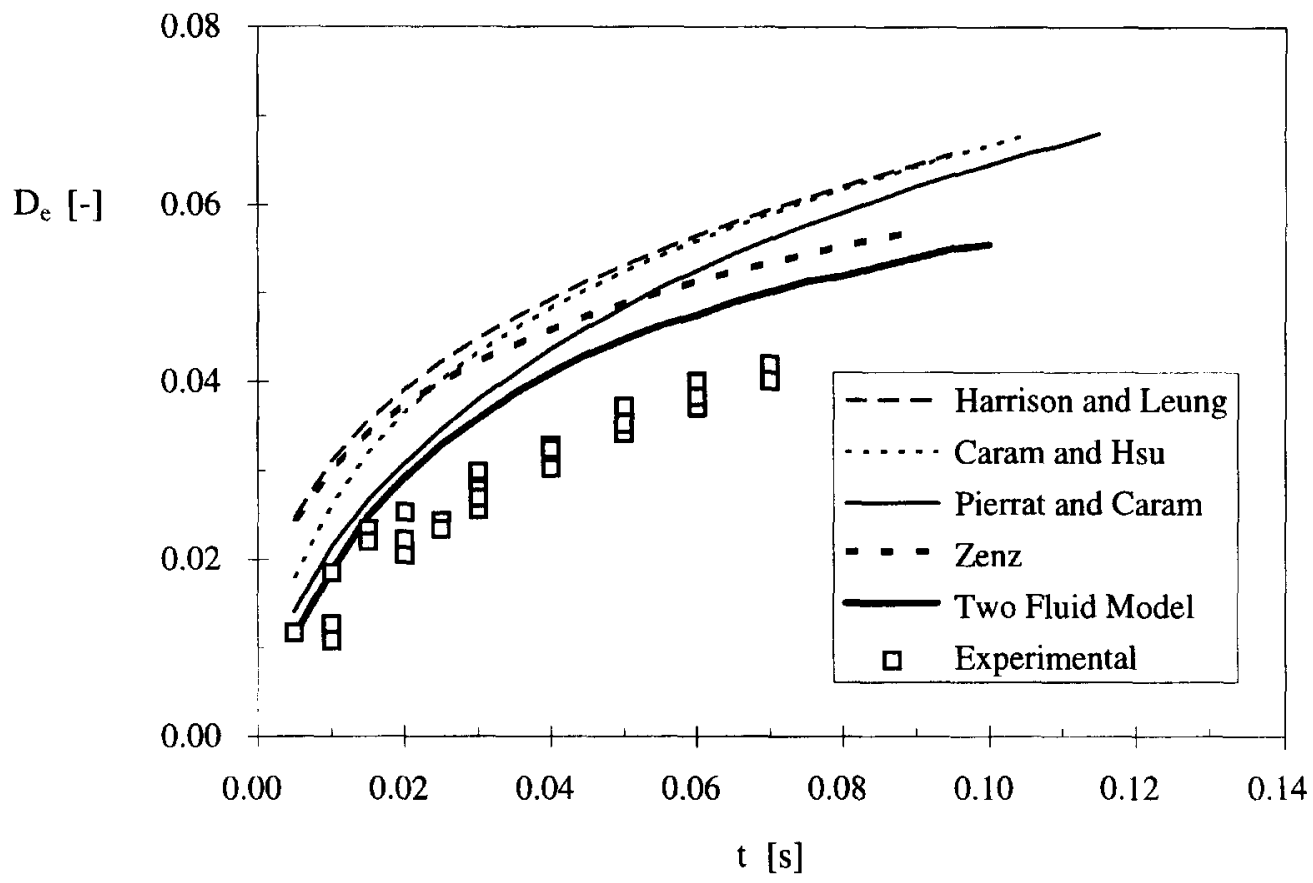

Fig. 10. Experimentally determined and theoretically calculated bubble diameters as a function of time for bubble growth in a semicircular gas-fluidised bed; $d_{p}=275 \mu \mathrm{m}, \rho_{\mathrm{s}}=3060 \mathrm{~kg} \mathrm{~m}^{-3}, u_{\mathrm{inj}}=20 \mathrm{~m} \mathrm{~s}^{-1}$.

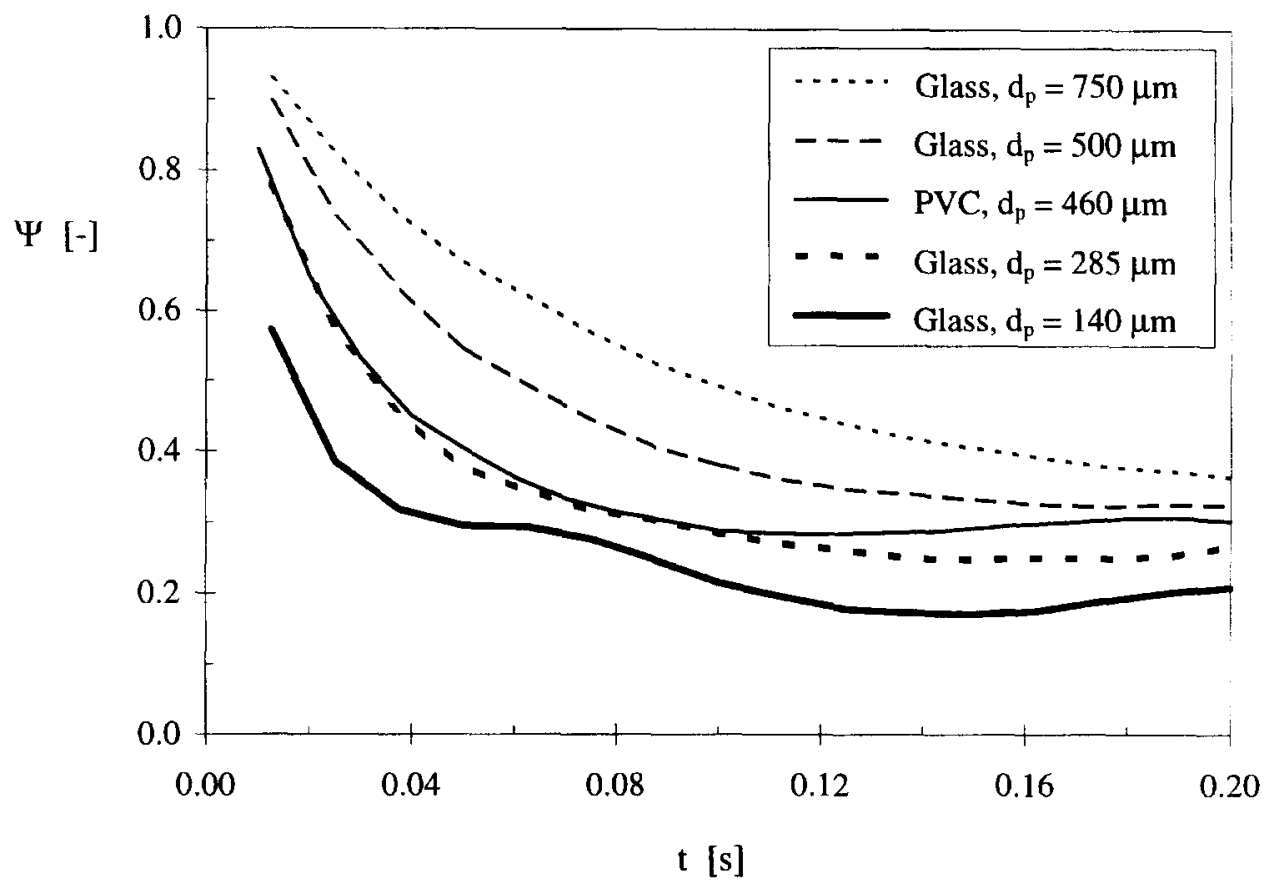

Fig. 11. Calculated leakage fraction during bubble growth in a two-dimensional gas-fluidised bed. Particle properties are listed in Table $2 ; u_{\text {inj }}=10 \mathrm{~m} \mathrm{~s}^{-1}$.

experimentally. Figures 13 and 14 show, respectively, the theoretically calculated bubble shape factor and the corresponding experimental counterpart during bubble growth in a three-dimensional gas-fluidised bed. The bubble shape factor $\sigma$ is defined as the maximum distance in vertical direction divided by the maximum distance in the horizontal direction:

$$
\sigma=\frac{D_{v}}{D_{h}}
$$

From Figs 13 and 14 it can be concluded that bubbles tend to become more elongated for coarser particles. 
The sharp decrease in the curves is caused by development of the bubble wake after bubble detachment.

5.2.3. Influence on bubble detachment times. Figure 15 shows the influence of particle size on bubble detachment times for several theoretical models. Considering the TFM, bubble detachment times are defined as the times at which the bubble contour closes above the orifice. The model proposed by Zenz predicts decreasing detachment times for increasing particle size, while the model of Caram and Hsu predicts slightly increasing values. The TFM predicts, together with the model of Harrison and Leung, a detachment time of approximately $0.2 \mathrm{~s}$, independent of particle size, which is in agreement with experimental observations.

\subsection{Influence of injection rate}

The influence of the injection velocity through the orifice on the process of bubble formation has been

Table 3. Particle properties; two series with the same minimum fluidisation velocity

\begin{tabular}{lccc}
\hline Series & $\begin{array}{c}d_{p} \\
(\mu \mathrm{m})\end{array}$ & $\begin{array}{c}\rho_{\mathrm{s}} \\
\left(\mathrm{kg} \mathrm{m}^{-3}\right)\end{array}$ & $\begin{array}{c}U_{\boldsymbol{m} f} \\
\left(\mathrm{~m} \mathrm{~s}^{-1}\right)\end{array}$ \\
\hline 1A & 425 & 4000 & 0.22 \\
1B & 500 & 2930 & 0.22 \\
1C & 750 & 1365 & 0.22 \\
2A & 603 & 4300 & 0.41 \\
2B & 750 & 2900 & 0.41 \\
\hline
\end{tabular}

investigated for the three-dimensional case. Here a comparison will be presented between theoretical results obtained from the TFM and the experimental data. In Fig. 16 the calculated bubble diameter is plotted as a function of the injected volume $(Q t)$ for several gas discharge rates through the orifice. All curves follow the same path of growth; the only difference is the faster expansion at higher injection rates. This is in agreement with experimental data which are shown in Fig. 17.

Although the models proposed by Harrison and Leung, and Zenz also predict the correct dependence for higher injection rates these models are unfortunately less suitable due to their incorrect description of the leakage, as shown before. The model proposed by Caram and $\mathrm{Hsu}$ produces bubble diameters which appear to be fully independent of the injection rate through the orifice, which is in contradiction with experimental observations. Of all approximate models only the model proposed by Pierrat and Caram produces the correct results. However, this model is of less practical value because no bubble detachment time is predicted.

As evident from eq. (31) the injection flow rate $Q$ also depends on the orifice diameter. A theoretical study using the TFM indicated that the influence of this parameter yielded similar results as depicted in Fig. 16.

\section{CONCLUSIONS}

A hydrodynamic model based on the two-fluid concept has been used to study bubble formation at

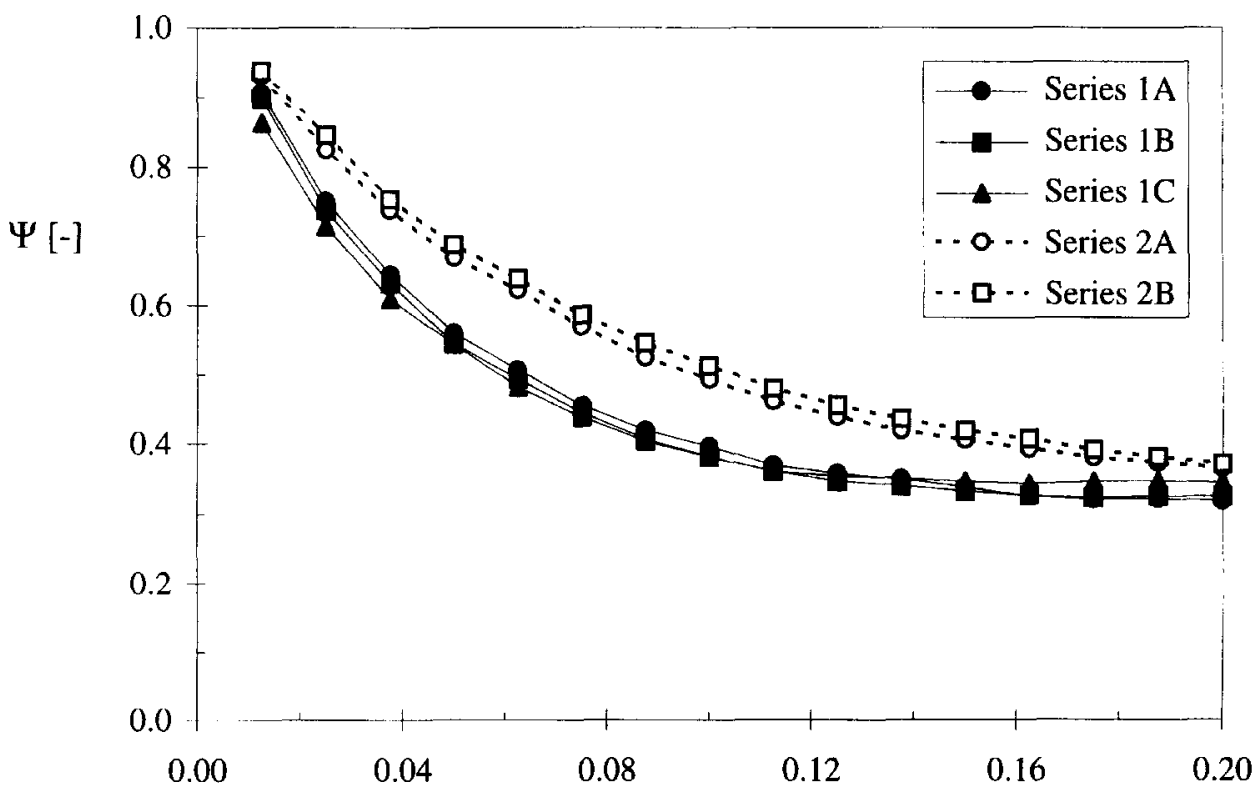

$t[s]$

Fig. 12. Calculated leakage fraction during bubble growth in a three-dimensional gas-fluidised bed. Particle properties are listed in Table $3 ; u_{\text {inj }}=20 \mathrm{~ms}^{-1}$; series 1: $U_{m f}=0.22 \mathrm{~ms}^{-1}$, series 2 : $U_{m f}=0.41 \mathrm{~ms}^{-1}$. 


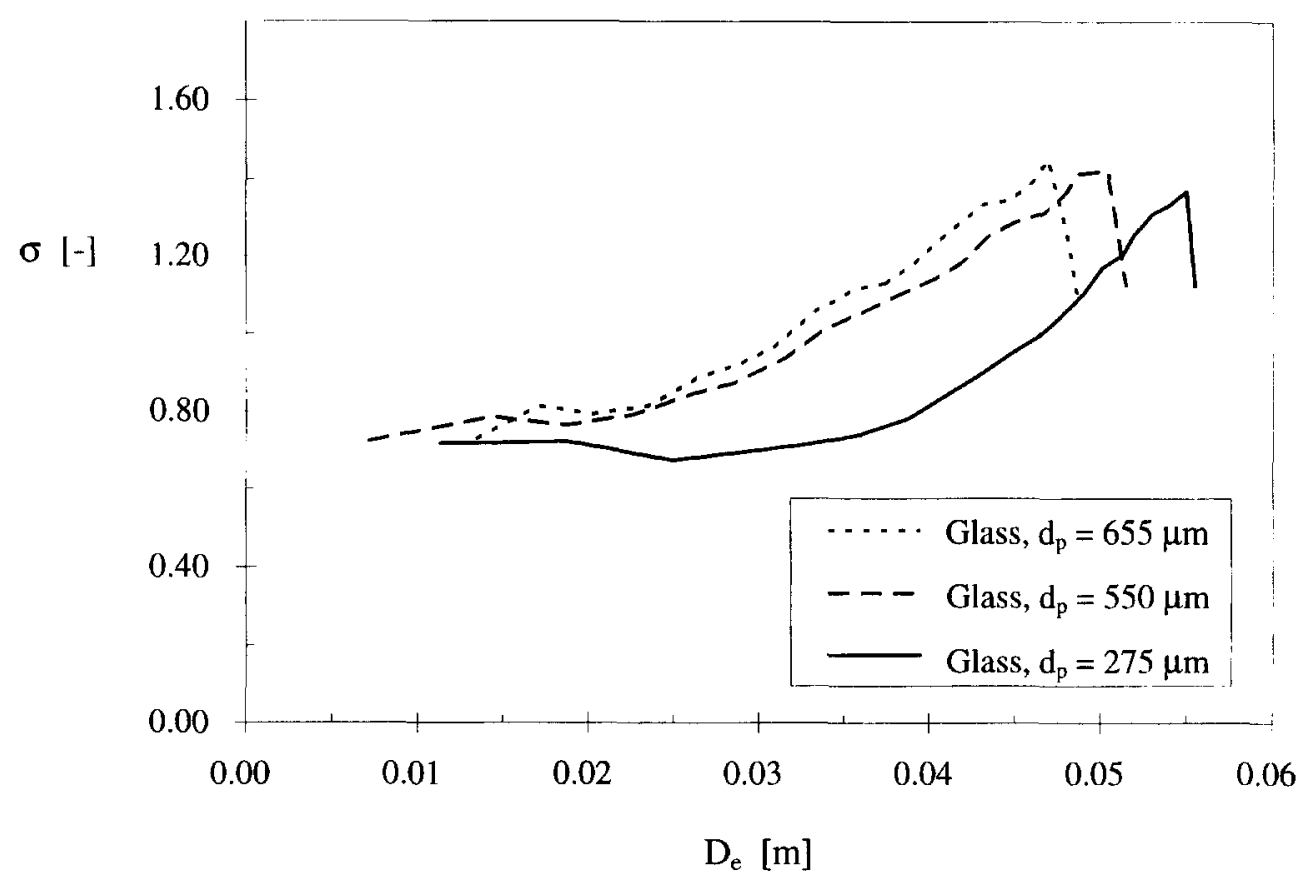

Fig. 13. Calculated bubble shape factor $\sigma$ for different particle sizes during bubble growth in a threedimensional gas-fluidised bed; $u_{\mathrm{inj}}=20 \mathrm{~m} \mathrm{~s}^{-1}$.

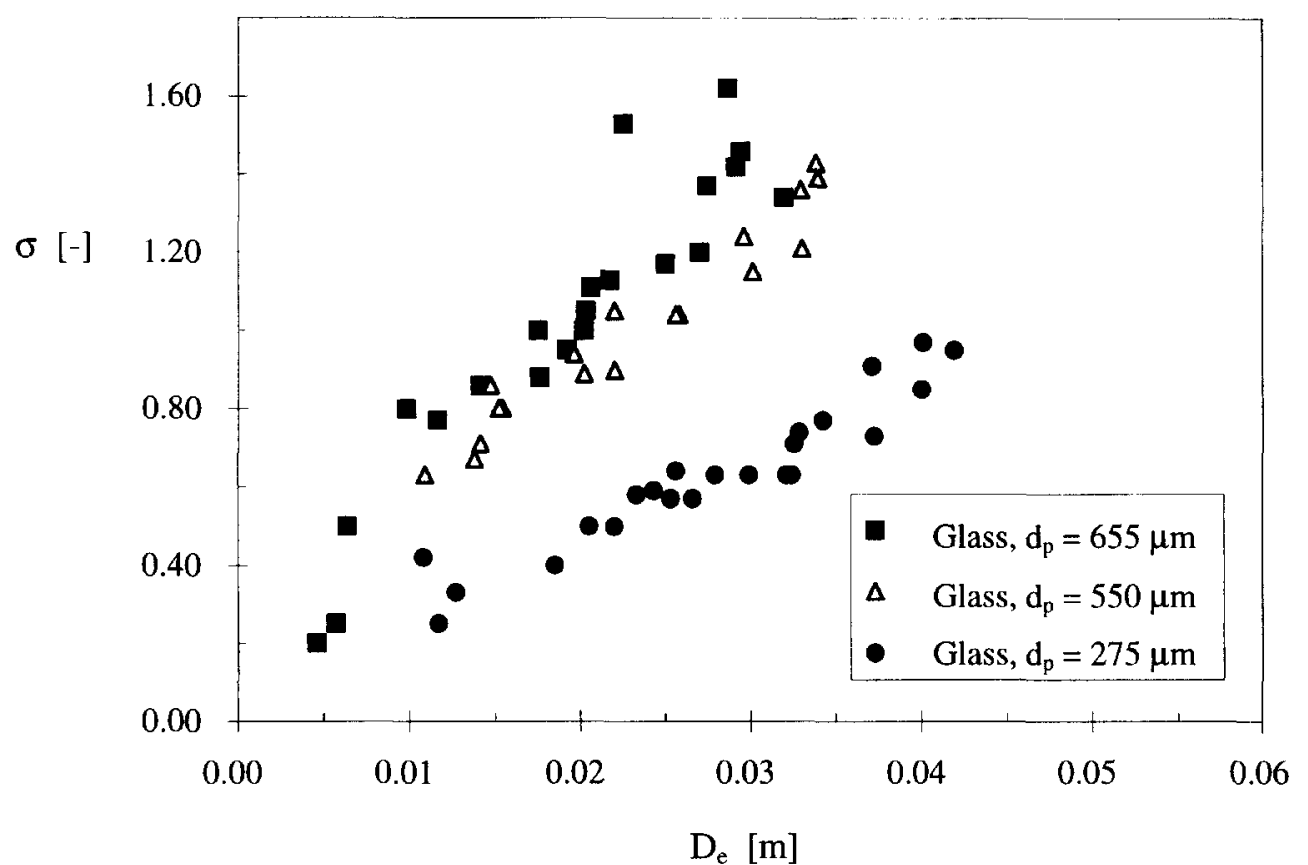

Fig. 14. Experimentally determined bubble shape factor $\sigma$ for different particle sizes during bubble growth in a three-dimensional gas-fluidised bed; $u_{\mathrm{inj}}=20 \mathrm{~m} \mathrm{~s}^{-1}$.

a single orifice in gas-fluidised beds. The theoretical results obtained from this model have been compared with experimental data and with results obtained from approximate bubble formation models, published in literature previously. To validate the hydrodynamic model (TFM) two cold-flow gas-fluidised beds (two-dimensional and three-dimensional) were constructed in which the bubble formation process could be observed photographically. The TFM appeared to be superior to the other models in predicting the bubble growth process and detachment times. Therefore, it is a valuable tool to predict bubble 


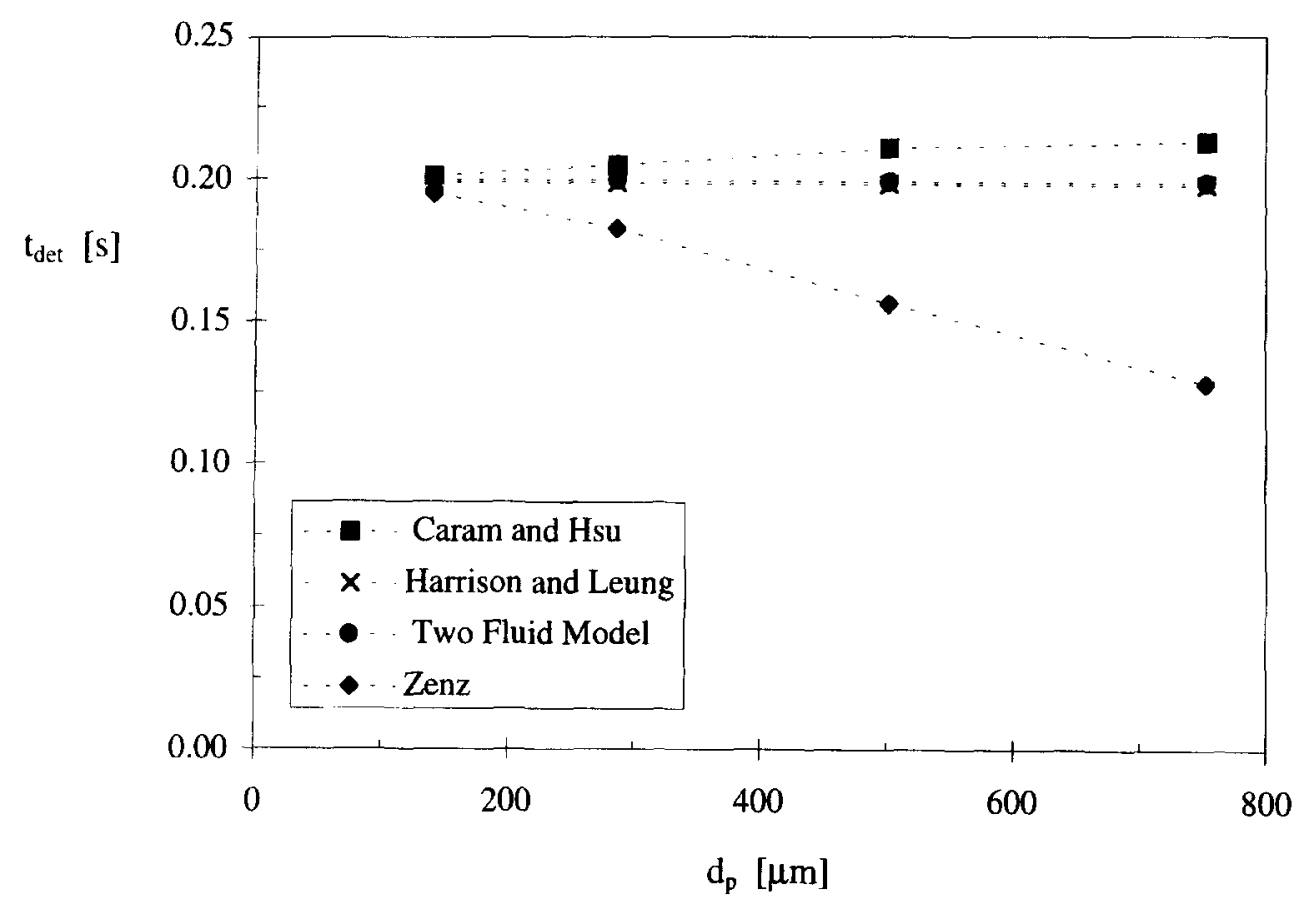

Fig. 15. Bubble detachment time in a two-dimensional gas-fluidised bed as a function of particle diameter for several theoretical models; $\rho_{\mathrm{s}}=2930 \mathrm{~kg} \mathrm{~m}^{-3}, u_{\mathrm{inj}}=10 \mathrm{~m} \mathrm{~s}^{-1}$.

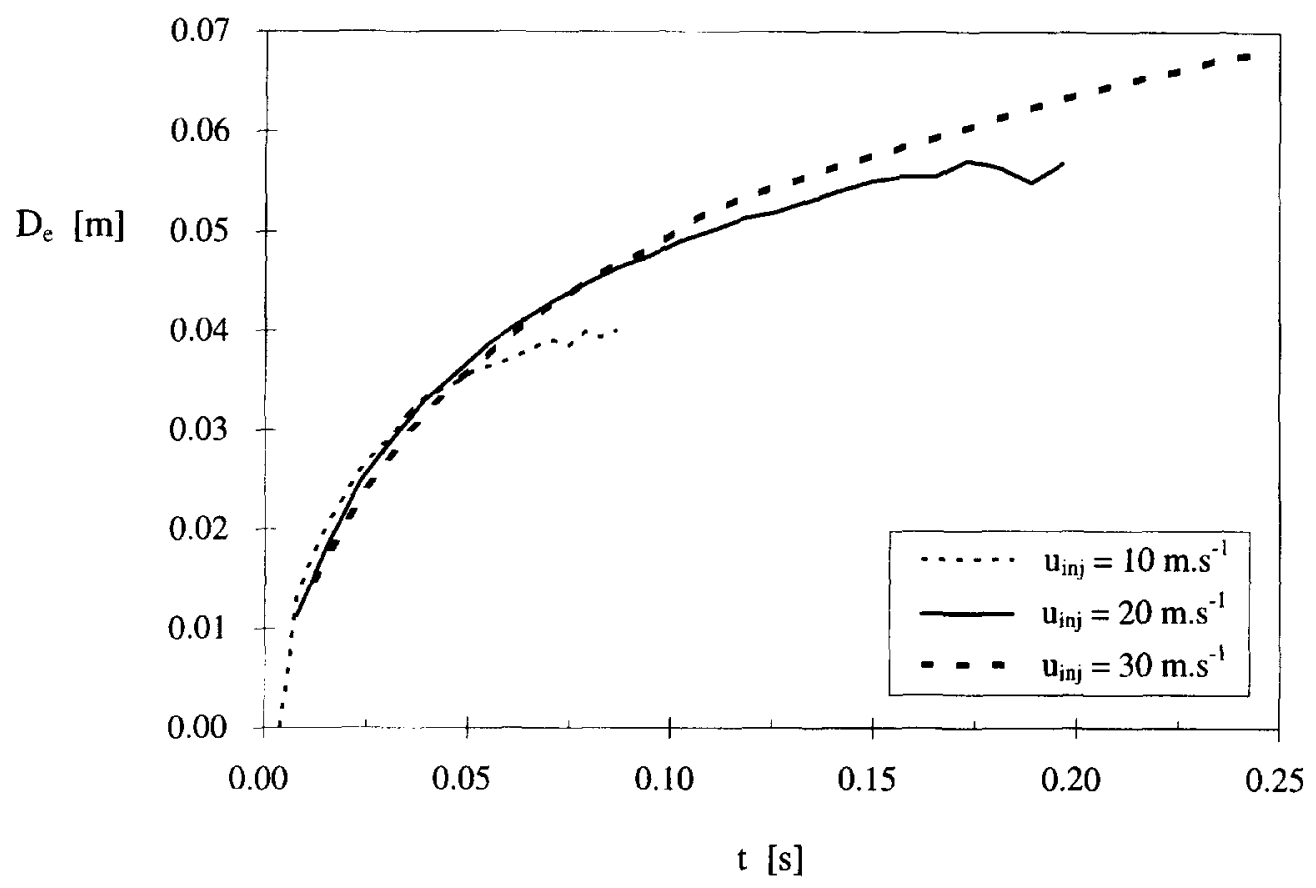

Fig. 16. Calculated bubble growth in a three-dimensional gas-fluidised bed for several gas discharge rates through the orifice; $d_{p}=275 \mu \mathrm{m}, \rho_{s}=3060 \mathrm{~kg} \mathrm{~m}^{-3}$.

formation in gas-fluidised beds theoretically. In contrast to the approximate models the TFM yields valuable information about the nonuniform gas exchange profile between a bubble and the surrounding emulsion phase. This information is useful to quantify the leakage which is of importance to predict grid zone conversion for fast heterogeneously catalysed reactions.

A systematic study has been conducted in which the effect of particle properties on the bubble formation process has been investigated. Large particles cause increasing leakage during bubble formation, resulting 


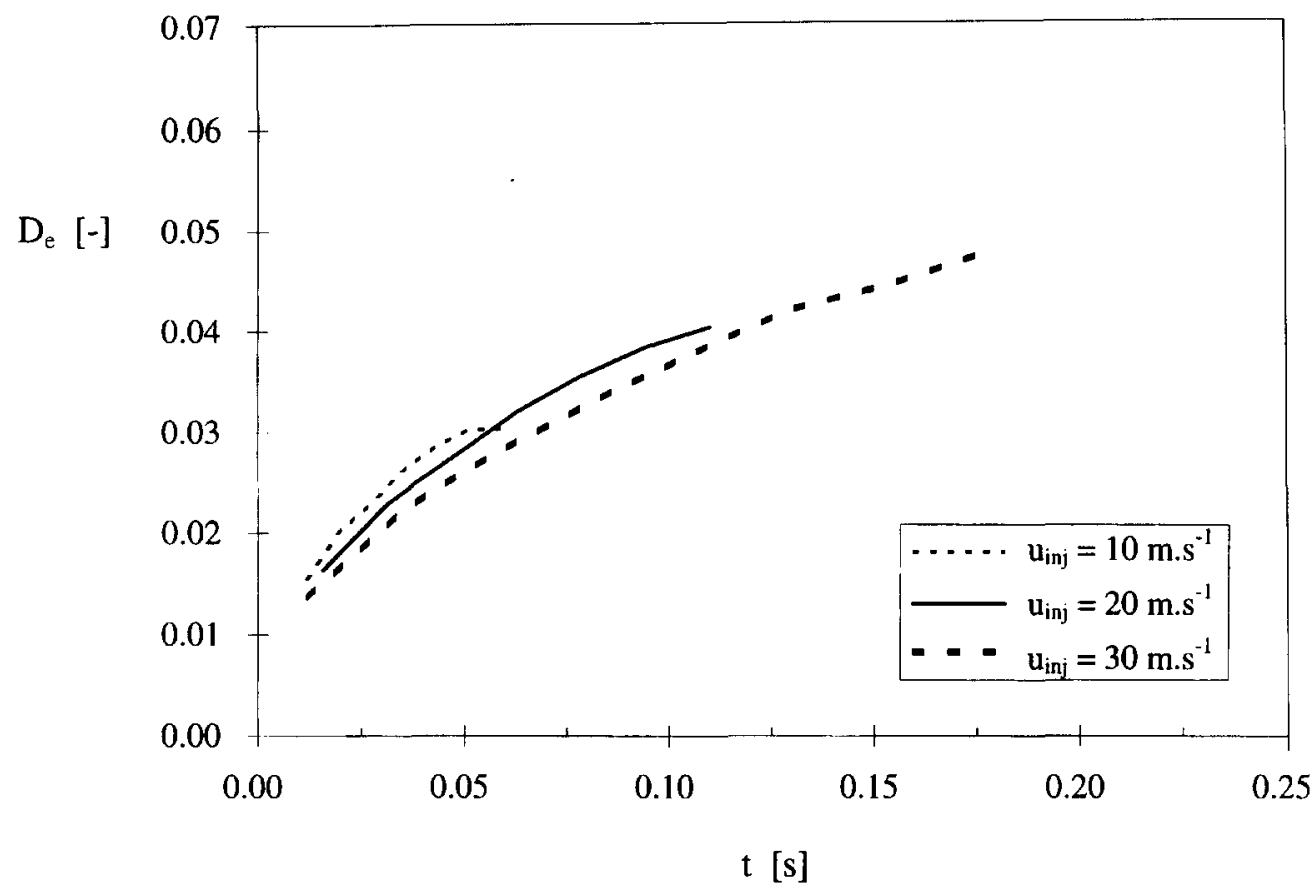

Fig. 17. Experimentally observed bubble growth in a three-dimensional gas-fluidised bed for several gas discharge rates through the orifice; $d_{p}=275 \mu \mathrm{m}, \rho_{s}=3060 \mathrm{~kg} \mathrm{~m}^{-3}$.

in smaller bubbles. The detachment time, however, is insensitive to the particle size. The influence of particle size and solid density on bubble growth appears to be determined by their effect on minimum fluidisation velocity: if $U_{m f}$ is constant, the bubble growth process will be unaltered. Furthermore, the influence of particle size on bubble shape has been studied. The TFM is the only model in which no specific assumption with respect to bubble shape has been made. This model predicts more elongated bubbles with increasing particle sizes, which is in agreement with experimental observations.

A theoretical study using the TFM to quantify the influence of injection flow rate (by varying both orifice velocity and orifice aperture) showed that growing bubbles follow the same path of growth; i.e. bubble diameter vs injected volume possesses a similar functional dependency. Because the detachment times are independent of the injection flow rate, higher injection flow rates result in larger bubbles. This finding was in quantitative agreement with experimental data, obtained in a semicircular gas-fluidised bed.

\section{NOTATION}

$H$

I

$k$

$K_{D}$

$M$

$n x$

ny

$N$

$P$

$Q$

$r$

$R$

$R_{g}$

$R e_{p}$

$s$

$S$

$t$

$\delta t$

$T$

u

U

v

V

$\boldsymbol{W}$

$\delta x$ particle diameter, $m$

bubble diameter, $m$

gravitational force per unit mass, $\mathrm{ms}^{-2} \quad \delta y$

particle-particle interaction modulus, $\mathrm{kg} \mathrm{m}^{-1} \mathrm{~s}^{-2}$ height, $\mathrm{m}$

unit tensor

kinetic energy, $\mathrm{m}^{2} \mathrm{~s}^{-2}$

Darcy's constant, $\mathrm{kg}^{-1} \mathrm{~m}^{3} \mathrm{~s}$

molecular mass, $\mathrm{kg} \mathrm{m}^{-3}$

number of computational cells in the horizontal direction

number of computational cells in the vertical direction

number of slices

pressure, $\mathrm{kg} \mathrm{m}^{-1} \mathrm{~s}^{-2}$

gas flow rate through the orifice, $\mathrm{m}^{3} \mathrm{~s}^{-1}$

radial coordinate, $\mathrm{m}$

bubble radius, $\mathrm{m}$

gas constant, $\mathrm{kg} \mathrm{m}^{2} \mathrm{~s}^{-2} \mathrm{~mol}^{-1} \mathrm{~K}^{-1}$

particle Reynolds number $\left[R e_{p}=\left(\rho_{f} \varepsilon \mid \mathbf{u}\right.\right.$

$\left.\left.-v \mid d_{p}\right) / \mu_{f}\right]$

axial position bubble centre, $m$

area, $\mathrm{m}^{2}$

time, $s$

time step used in numerical solution procedure, $s$

temperature, $\mathbf{K}$

interstitial gas velocity, $\mathrm{m} \mathrm{s}^{-1}$

superficial gas velocity, $\mathrm{m} \mathrm{s}^{-1}$

solids velocity, $\mathrm{m} \mathrm{s}^{-1}$

bubble volume, $\mathrm{m}^{3}$

width, $\mathrm{m}$

horizontal dimension of a computational cell, $\mathrm{m}$

vertical dimension of a computational cell, $\mathrm{m}$

thickness of bubble slice, $\mathrm{m}$ 


\section{Greek symbols}

$\beta \quad$ interphase momentum transfer coefficient, $\mathrm{kg} \mathrm{m}^{-3} \mathrm{~s}^{-1}$

$\varepsilon \quad$ phase volume fraction

$\mu \quad$ shear viscosity, $\mathrm{kg} \mathrm{m}^{-1} \mathrm{~s}^{-1}$

$\xi \quad$ bulk viscosity, $\mathrm{kg} \mathrm{m}^{-1} \mathrm{~s}^{-2}$

$\rho$ density, $\mathrm{kg} \mathrm{m}^{-3}$

$\sigma \quad$ shape factor

$\tau \quad$ viscous stress tensor, $\mathrm{kg} \mathrm{m}^{-1} \mathrm{~s}^{-2}$

$\phi \quad$ velocity potential, $\mathrm{m}^{2} \mathrm{~s}^{-1}$

$\psi \quad$ integral leakage fraction

$\begin{array}{ll}\text { Subscripts } \\ \text { det } & \text { detachment } \\ b & \text { bed } \\ e & \text { equivalent } \\ \mathrm{em} & \text { emulsion phase } \\ \mathrm{ex} & \text { exchange } \\ f & \text { fluidum or free-board } \\ h & \text { horizontal } \\ \text { inj } & \text { injected } \\ m f & \text { minimum fluidisation } \\ o & \text { orifice } \\ p & \text { particle } \\ R & \text { at position } r=R \\ s & \text { solid phase } \\ v & \text { vertical } \\ 0 & \text { initial value } \\ \infty & \text { infinitely away }\end{array}$

Superscripts

$T \quad$ transposed

\section{REFERENCES}

Bird, R. B., Stewart, W. E. and Lightfoot, E. N., 1960 , Transport Phenomena, pp. 79, 199. Wiley, New York.

Caram, H. S. and Hsu, K. K., 1986, Bubble formation and gas leakage in fluidized beds. Chem. Engng Sci. 41(6), $1445-1453$

Davidson, J. F. and Harrison, D., 1963, Fluidised Particles, pp. 128-129. Cambridge University Press, Cambridge, U.K.

Ding, J. and Gidaspow, D., 1990, A bubbling fluidisation model using kinetic theory of granular flow. A.I.Ch.E. J. 36(4), 523-538.
Gidaspow, D., 1986, Hydrodynamics of fluidization and heat transfer: supercomputer modelling. Appl. Mech. Rev. 39(1), $1-15$.

Gidaspow, D. and Ettehadieh, B., 1983, Fluidization in twodimensional beds with a jet; part 2: hydrodynamic modelling. Ind. Engng Chem. Fundam. 22, 193-201.

Hagyard, T. and Sacerdote, A. M., 1966, Viscosity of suspensions of gas-fluidized spheres. Ind. Engng Chem. Fundam. 5, 500-508.

Hailu, L., Plaka, F., Clift, R. and Davidson, J. F., 1993, Measurement of gas flow through a two-dimensional bubble in a fluidised bed. Trans Instn Chem. Engrs 71, Part A, 382-389.

Harrison, D. and Leung, L.S., 1961, Bubble formation at an orifice in a fluidised bed. Trans Instn Chem. Engrs 39, $409-414$.

Kuipers, J. A. M., 1990, A two-fluid micro balance model of fluidized beds. Ph.D. dissertation, Twente University, Enschede, The Netherlands.

Kuipers, J. A. M., Prins, W. and van Swaaij, W. P. M., 1991, Theoretical and experimental bubble formation at a single orifice in a two-dimensional gas-fluidized bed. Chem. Engng Sci. 46(11), 2881-2894.

Kuipers, J. A. M., Tammes, H., Prins, W. and van Swaaij, W. P. M., 1992, Experimental and theoretical porosity profiles in a two-dimensional gas-fluidized bed with a central jet. Powder Technol. 71, 87-99.

Kuipers, J. A. M., van Duin K. J., van Beckum, F. P. H. and van Swaaij, W. P. M., 1993, Computer simulation of the hydrodynamics of a two-dimensional gas-fluidized bed. Comput. Chem. Engng 17(8), 839-858.

Nguyen, X. T. and Leung, L. S., 1972, A note on bubble formation at an orifice in a fluidised bed. Chem. Engng Sci. 27(7), 1748-1750.

Pierrat, P. and Caram, H. S., 1992, Bubble formation and gas leakage in beds at minimum fluidization conditions, in Fluidization VII (Edited by O. E. Potter and D. J. Nicklin), pp. 93-101. Engineering Foundation, New York.

Rowe, P. N., MacGillivray, H. J. and Cheesman, D. J., 1979, Gas discharge from an orifice into a gas fluidized bed. Trans Instn Chem. Engrs 57, 194-203.

Schiller, L. and Naumann, A., 1935, Über die grundlegenden Berechnungen bei der Schwerkraftaufbereitung. Z. Ver. Dtsch. Ing. 77, 318-326.

Schügerl, K., Merz, M. and Fetting, F., 1961, Rheologische Eigenschaften von gasdurchströmten Fliessbettsystemen. Chem. Engng Sci. 15(1), 1-38.

Wen, Y. C. and Yu, Y. H., 1966, Mechanics of fluidization. Chem. Engng Prog. Symp. Ser. 62(62), 100-111.

Yang, W. C., Revay, D., Anderson, R. G., Chelen, E. J., Keairns, D. L. and Cicero, D. C., 1984, Fluidization phenomena in a large-scale cold flow model, in Fluidization $I V$ (Edited by D. Kunii and R. Toei), pp. 77-85. Engineering Foundation, New York.

Zenz, F. A., 1968, Bubble formation and grid design. Instn Chem. Engng Symp. Ser. 30, 136-139. 